\title{
Human skin volatiles: passive sampling and GC $\times$ GC-ToFMS analysis as a tool to investigate the skin microbiome and interactions with anthropophilic mosquito disease vectors
}

\author{
Alexis P. Roodta, Yvette Naudéa $^{\star}$, Anton Stoltz ${ }^{b}$, Egmont Rohwera \\ aDepartment of Chemistry, Faculty of Natural and Agricultural Sciences, University of Pretoria, Pretoria, South Africa.

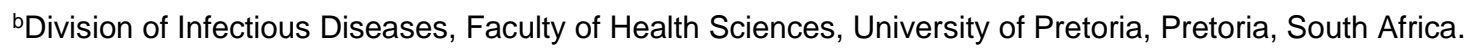

${ }^{*}$ Corresponding author: Department of Chemistry, University of Pretoria, Private Bag x20, Hatfield, 0028, South Africa. Email: yvette.naude@up.ac.za

\section{Highlights}

- Passive sampling of volatiles emanating from human skin surface using non-invasive PDMS bracelets and anklets.

- Thermal desorption of bracelets and anklets and analysed by GC × GC-TOFMS.

- Method generates large numbers of biomarker candidates.

- Compounds linked to blood-host selection by anthropophilic mosquito species and resident skin microbiome were identified.

- Relative abundances of compounds were compared between wrist and ankle and between individuals.

\begin{abstract}
Volatile organic compounds (VOCs) emanating from the surfaces of human skin are of great interest to researchers in medical and forensic fields, as well as to biologists studying the ecology of blood-feeding insect vectors of human disease. Research involving the comparison of relative abundances of VOCs emanating from human skin is currently limited by the methodology used for sample collection and pre-concentration. The use of in-house developed silicone rubber (polydimethylsiloxane (PDMS)) passive sampling devices constructed in the form of bracelets and anklets was explored to address this need. The easy-to-use samplers were employed as non-invasive passive sampling devices for the non-targeted collection and concentration of volatile human skin emissions prior to thermal desorption thereof coupled with comprehensive gas chromatographic time-offlight mass spectrometric $(G C \times$ GC-TOFMS) analysis. Compounds collected were from a wide range of compound classes. Several compounds, notably cyclic ketones, identified have not been previously reported in skin volatile literature. Comparison of normalized unique mass peak area signals has revealed relative quantitative differences and similarities between the samples collected from two individuals' wrists and as well as between an individual's wrist and ankle. The sampling method was evaluated based on its ability to provide many candidate compounds for potential biomarker discovery. The results show the ability of the new sampling method for augmenting the current knowledge on human skin volatile emissions. The samplers are both easy to use and economical. Applications explored include the study of the complex relationships between the human skin microbiome and the attractiveness of individuals to anthropophilic blood host seeking mosquitoes.
\end{abstract}

Keywords: Human skin volatiles; GCxGC-ToFMS; non-invasive passive sampling; skin microbiome; mosquito semiochemicals 


\section{Introduction}

Investigations into the volatile organic compounds (VOCs) making up the human skin's volatilome are of interest to researchers in many fields. Applications include metabolomics studies [1], the identification of individuals in forensic science [2], exploring the symbiotic relationships between human hosts and resident skin microflora [3], as well as studying the host seeking preference of blood-feeding mosquito vectors of human disease [4]. The last mentioned application is of great interest in the ongoing search for new ways to efficiently control mosquito transmitted pathogens which cause human diseases around the world through the development of effective push-pull strategies for mosquito control [5].

Investigations of the human volatilome in a metabolomics context may draw on a variety of bodily secretions as sources of metabolites. Studies focusing on volatiles emitted by urine, blood, exhaled breath and skin secretions are widely reported [1]. Several publications have probed the human skin volatilome in recent years [6]. Endogenous volatiles making up the human skin volatilome originate from both human cells and the resident skin microflora [7]. The surface of human skin forms a unique microbiome which is colonized by a cohort of endogenous microflora. The species composition and diversity of which can play a role in an individual's skin volatile profile [8] and attractiveness to the malaria vector mosquito species Anopheles gambiae sensu stricto [9]. The study of external factors which affect the human skin microbiome abundance and distribution and how these factors influence the attractiveness of human skin to blood host seeking insects is still in its infancy with very few peer reviewed journal articles addressing the complex topic.

A wide range of sample collection approaches have been reported for the analysis of human skin volatiles, most commonly, in combination with gas chromatography mass spectrometry (GC-MS) [10]. Researchers have made use of glass beads or adsorptive textile materials, socks [11], teflon bags or sleeves [12], or cellusose film bags [13], which are placed in contact with skin surfaces for the collection of skin secretions. The corresponding analyses most often yield predominantly qualitative information, although comparisons of relative abundances of skin VOCs between samples collected using both glass beads [14] and cotton patches [15] have been reported. Relative abundances of skin VOCs, in addition to the qualitative identification of skin volatiles, are of importance when investigating human semiochemicals and the role of the human skin microflora in attracting blood-host seeking mosquitoes [16]. Differences in relative abundances of skin volatiles have also been linked to differing attractiveness of human blood hosts to anthropophillic Aedes aegypti mosquitoes [4].

Currently, research focused on the study of the human skin's volatilome is limited by difficulties associated with sample collection. Simple and reliable methods of collecting and screening of the relative abundances of skin volatiles are required. Such methods may provide candidate biomarkers responsible for the interactions between the skin surface microbiome and blood-host seeking mosquitoes prior to high throughput and robust targeted analyses.

Polydimethylsiloxane (PDMS) is a material which has shown promise for its functionality, in the form of patches placed on the skin surface, as an absorbent material for the passive sampling of skin chemicals [17 - 20]. This material is ideal for passive sampling applications due to its ability to sequester a broad range of volatile analytes from the surrounding atmosphere during sampling. In addition, the ability for the material to exclude 
water during sampling and compatibility with thermal desorption sample introduction techniques makes it ideal for non-targeted screening of skin volatiles with relatively few steps involved during the sample collection process. The use of PDMS material for the comparisons of time weighted average abundances of skin chemicals between different skin regions has not been previously reported to the best of our knowledge. The goal of this study was to explore the number and diversity of compounds collected during passive sampling, as well as to compare relative abundances analytes emanating from the wrists and ankles of human skin. This was performed by application of an in-house developed PDMS loop passive samplers in combination with comprehensive two-dimensional gas chromatography time-of-flight mass spectrometry (GC×GC-ToFMS). In doing so, the relative abundances of collected volatiles may be evaluated in the context of their link to the human skin microbiome and semiochemicals affecting the blood host selection of anthropophilic mosquito species.

\section{Material and methods}

\subsection{Chemicals}

Methanol (AR 99.5\%), acetone (AR 98.0\%), and acetonitrile (AR 99.5\%), were purchased from Merck, South Africa. For GC linear retention index determination, $n$-alkanes $\mathrm{C}_{12}-\mathrm{C}_{28}$ were used (Merck, Pretoria, South Africa).

\subsection{In-house constructed PDMS sorptive passive sampler}

Passive sampler loops were manufactured by cutting lengths of polydimethylsiloxane tubing (Class VI USP Medical Grade Silicone tubing, $0.305 \mathrm{~mm}$ ID, $0.635 \mathrm{~mm}$ OD, Technical Products Inc. of Georgia, USA) to predetermined lengths which would allow for their easy and comfortable use as bracelets and anklets. Wrist and ankle samplers were constructed from tubing of lengths 180 and $240 \mathrm{~mm}$ respectively. A small piece of uncoated silica capillary column $(0.25 \mathrm{~mm}$ ID) (SGE Analytical Science, Separation Scientific (Pty) Ltd, South Africa) was inserted to connect the two ends of the tube in order to form a closed loop (Figures 1 and 2). The masses of the PDMS material were $0.0573 \pm 0.0025 \mathrm{~g}$ and $0.0750 \pm 0.0024 \mathrm{~g}$ for bracelet and anklet samplers respectively.

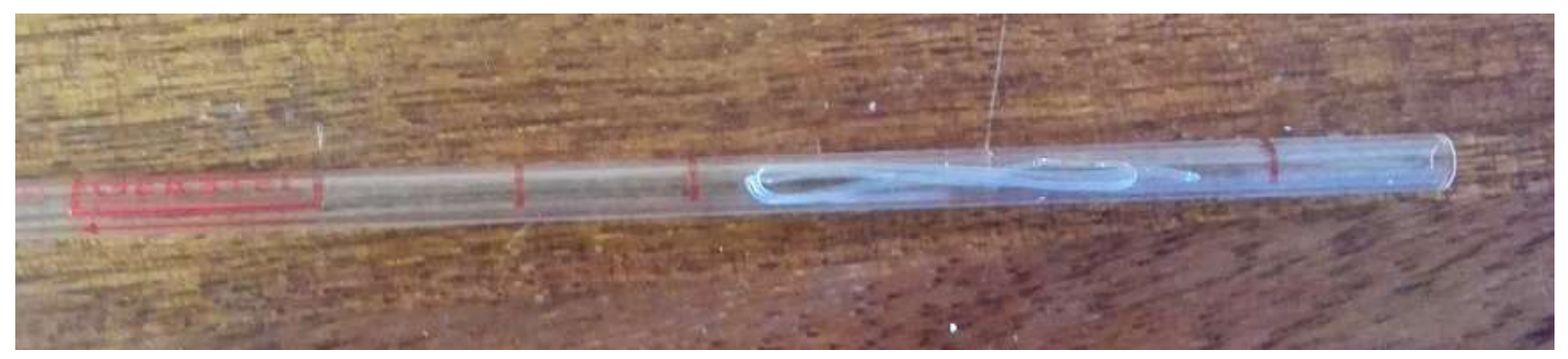

Figure 1. PDMS loop sampler inserted into a thermal desorption tube. 


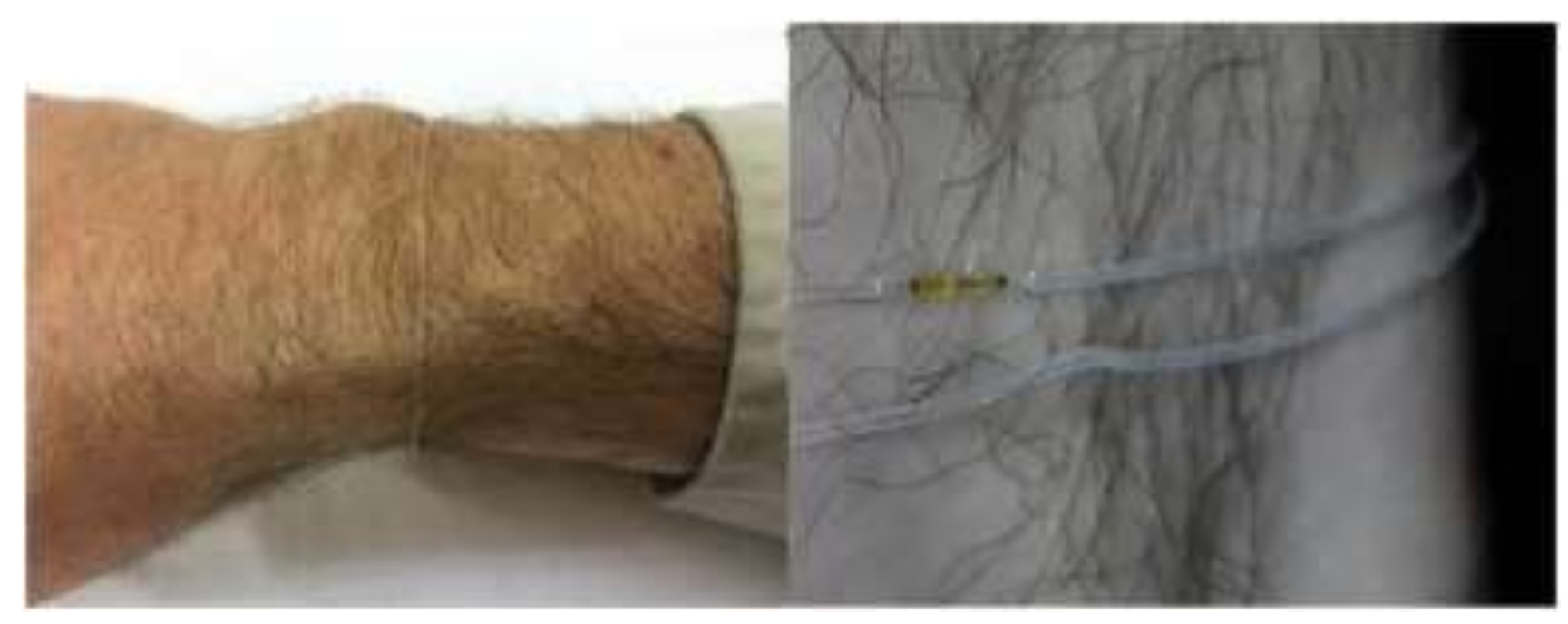

Figure 2. Wrist (Left) and ankle (Right) sampling using a PDMS loop passive sampling device.

Prior to use all samplers were cleaned and conditioned. Samplers were subjected to three rounds of solvent extraction using a mixture of acetone and methanol $(1: 1, v / v)$. Glass vials containing the solvent and samplers were sonicated for five minutes between solvent exchanges. The samplers were placed in $17.8 \mathrm{~cm}$ long glass desorption tubes (4 mm ID, $6 \mathrm{~mm}$ OD) (Gerstel, Chemetrix, South Africa) and then conditioned with hydrogen gas (Afrox, South Africa) at $100 \mathrm{~mL} / \mathrm{min}$ for ten hours at $280^{\circ} \mathrm{C}$ in an off-line tube conditioning system (Gerstel, Chemetrix, South Africa) after which three more solvent extractions were performed using acetonitrile. The samplers were tapped against the inside wall of a glass beaker to remove excess solvent before being sealed in a glass vial until deployment.

\subsection{VOC collection}

\subsubsection{Duration-based skin sampling}

In order to investigate the performance of the passive sampling and analysis approach under temperature controlled conditions, sampling of skin volatiles was first performed in a laboratory environment for different durations of time. This was achieved by analysis of samplers worn on the non-dominant wrist of a Caucasian male volunteer (Subject 1, age 26) for a total duration of nine hours. During this time a sampler was removed and immediately analysed every ninety minutes. Sampling was conducted in a temperature controlled environment to reduce the effect of this variable on skin volatile absorption by the passive samplers. In addition to skin volatile samples, unused sampler blanks and background laboratory air were also sampled for the full nine hour duration of the experiment. 


\subsubsection{Collection of replicate samples from ankles and wrists of two individuals}

A set of skin volatile samples were collected from a Caucasian male (Subject 1, self-described as not attractive to mosquitoes), age 26, using the PDMS passive sampling loops (Figure 2). The ambient temperature during the simultaneous sampling of the individual's wrist and ankle was maintained at $21^{\circ} \mathrm{C}$. Passive samplers were worn for a duration of four hours in direct contact with the subject's skin on the non-dominant wrist of the subject and corresponding ankle. Five replicate samples were collected from each sampled region. Two sampler blanks and three laboratory background samplers were also analysed. In addition, a single sample was collected from the same wrist and ankle of the sampled individual in an alternative environment, namely the subject's office. Samplers from the individual's wrist and ankle were analysed by GC×GC-ToFMS in alternating order to avoid bias in the results due to length of storage time. Samplers were individually sealed in glass vials and kept at $-80^{\circ} \mathrm{C}$ for no more than 72 hours before analysis. This method of storage was adopted since it has been shown to result in no statistically significant changes in the abundances of human skin analytes collected in PDMS passive samplers stored for up to 21 days [17].

In an additional two separate sample collections, two sets of samples were collected from the non-dominant wrist of a second Caucasian male volunteer (Subject 2, self-described as attractive to mosquitoes), age 24. Passive samplers were worn by the subject for a duration of four hours while the subject slept. No effort was made to control any environment parameters during sampling. Three background samples were collected in the room where the subject slept on each occasion, as well as quality control samples. In addition, samples were collected in an alternative environment, namely, the subject's office work place. The two sets of samples were collected three months apart during the winter and spring seasons. All samples from both sampling sample sets were kept at $-80^{\circ} \mathrm{C}$ and analysed within 24 hours of being collected.

\subsubsection{Ethical Considerations}

All subjects who were sampled during the course of this work gave written consent to participate and no special hygiene or dietary requirements were imposed. Ethical clearance was provided by the ethics committee of the Faculty of Natural and Agricultural Sciences at the University of Pretoria (Reference number EC160606-044).

\subsection{Instrumentation}

\subsubsection{Desorption of analytes in a thermal desorption system (TDS)}

Compounds concentrated in the samplers were thermally desorbed by heating the samplers in a thermal desorption system (Gerstel TDS) from $30^{\circ} \mathrm{C}$ (hold $3 \mathrm{~min}$ ) at $60^{\circ} \mathrm{C} / \mathrm{min}$ to $280^{\circ} \mathrm{C}$ (hold $10 \mathrm{~min}$ ) with a desorption flow rate of $100 \mathrm{~mL} / \mathrm{min}$ at a vent pressure of $10 \mathrm{psi}$ (helium 5.0, Afrox, South Africa). The TDS transfer line temperature was $350^{\circ} \mathrm{C}$. The desorbed analytes were cryogenically focused at $-100{ }^{\circ} \mathrm{C}$ using liquid nitrogen (Afrox, South Africa) in a cooled injection system (CIS) (Gerstel CIS 4) with an empty, baffled, deactivated glass liner. After desorption a splitless injection (purge on $1.5 \mathrm{~min}$, purge flow $30 \mathrm{~mL} / \mathrm{min}$, solvent 
vent mode) was performed by heating the $\mathrm{CIS}$ from $-100^{\circ} \mathrm{C}$ at $10{ }^{\circ} \mathrm{C} / \mathrm{s}$ to $250^{\circ} \mathrm{C}$ and held there for the duration of the GC run.

\subsubsection{Analysis by GC×GC-ToFMS}

Separation of compounds was performed on a LECO Pegasus 4D GC $\times G C-T o F M S$ system. The system consists of an Agilent@ 7890 GC (LECO Africa (Pty)) Ltd., Kempton Park, South Africa) modified to contain a dual stage modulator and secondary oven. Nitrogen gas cooled with liquid nitrogen was used for the cold jets and synthetic air for the hot jets. The primary column was connected to the secondary column with a press-tight column connector (Restek, Bellefonte, PA, USA). ChromaTOF software (Version 4.50.8.0 optimised for Pegasus, LECO Africa (Pty) Ltd.) was used to operate the instrument, for data capturing and data processing. A column set consisting of Rxi-1 MS, $30 \mathrm{~m} \times 0.25 \mathrm{~mm}$ ID $\times 0.25 \mu \mathrm{m}$ film thickness in the first dimension (1D) and Rxi-17Sil MS $1 \mathrm{~m} \times 0.25 \mathrm{~mm} \times 0.25 \mu \mathrm{m}$ film thickness in the second dimension (2D) (Restek, Bellefonte, PA, USA) was used.

The primary oven temperature programme was $40^{\circ} \mathrm{C}$ (held for $1.5 \mathrm{~min}$ ) then ramped at $10^{\circ} \mathrm{C} / \mathrm{min}$ to $300{ }^{\circ} \mathrm{C}$ (held for $8 \mathrm{~min}$ ). The GC run time was $35.5 \mathrm{~min}$. The secondary oven was offset by $+5^{\circ} \mathrm{C}$ relative to the primary oven. The modulator temperature was offset by $15^{\circ} \mathrm{C}$ relative to the secondary oven temperature. The modulation period was $3 \mathrm{~s}$ (hot pulse time of $0.80 \mathrm{~s}$ ). The carrier gas (helium 5.0, Afrox, South Africa) flow rate was $1.4 \mathrm{~mL} / \mathrm{min}$ in the constant flow mode. The MS transfer line temperature was set at $300^{\circ} \mathrm{C}$. The electron ionization (EI) ion source temperature was $230^{\circ} \mathrm{C}$, the electron energy was $70 \mathrm{eV}$, the detector voltage was set at $1570 \mathrm{~V}$, data acquisition rate was 100 spectra/s and the mass acquisition range was 35-500 Da.

\subsection{Data processing}

\subsubsection{Chromatographic peak alignment}

Peak table data generated during initial data processing were aligned using ChromaToF Statistical Compare software (LECO (Pty)). A minimum mass spectral similarity match of 600 was used with variation in retention times being limited to one modulation period in the first dimension (1D) and $0.1 \mathrm{~s}$ in the second dimension (2D). Peak finding was performed using an initial $\mathrm{S} / \mathrm{N}$ threshold of 100 and a secondary threshold of 20 for peaks not aligned during the initial alignment.

\subsubsection{Peak area normalization}

Two approaches to the normalization of peak areas in skin volatiles were compared during the development of the method. Normalization was based on (i) the mass spectral total useful signal (MSTUS) of each sample [21] and (ii) the mass of PDMS in each individual sampler. Normalization involved using the chromatographic peak area corresponding to the unique mass for each analyte peak as a numerator. This value was then divided by, 
either, (i) the MSTUS, which corresponds to the sum total of all unique mass peak areas of all potential skin volatiles in each sample, or (ii) the mass of PDMS in each sampler. Comparisons of chromatographic peak areas found in skin samples to the corresponding peaks found in background samples were based on normalization to the mass of PDMS used in each sampler.

\subsubsection{Data analysis}

Processing of the data generated after the analysis of skin volatile samples collected at ninety minute intervals for a total duration of nine hours (2.3.1) involved the initial peak alignment of the six skin samples and respective quality control samples. The resultant list of chromatographic peak markers was further reduced to include only those peaks observed exclusively in skin sample chromatograms. This data could be further categorized by classification of peaks according to their retention time on the primary column $\left(T_{R 1}\right)$ during the separation. Processing of the data collected during the second set of experiments (2.3.2) involved several steps. Since the passive samplers were exposed to the exogenous atmosphere during sampling, the first steps involved in the processing of chromatographic data aimed to remove peaks which arise due to the sampling environment and contamination during analysis of samplers. For this purpose, chromatographic peaks which were not found in at least $80 \%$ of skin samples collected from respective sampling sites, as well as the corresponding skin sample in an alternative sampling environment were removed from the aligned chromatographic peak data as the first step of data analysis. Furthermore, chromatographic peaks which were found in the background sampling environment samples which had peak areas greater than $10 \%$ of the corresponding average peak area in skin samples were excluded from comparisons of relative peak areas between samples. This threshold was used as a conservative starting point in order to focus data processing on volatiles emanating from the skin surface. Peak table entries were assigned tentative identifications based on mass spectral library similarity scores above 750 for entries in the NIST/EPA/NIH Mass Spectral Library (EI) (2016). In addition, the linear temperature programed retention index (LTPRI) was calculated using the average first dimension retention time for each peak marker in the aligned sample data sets using Van den Dool's equation [21] in order to further confirm these tentative identifications by comparison to literature values.

\subsubsection{Peak area comparisons}

In addition to the tentative identification of analytes emanating from the skin surface, selected compounds' relative abundances were compared between samples after normalization. Technical variability in the measured peak areas was assessed by calculating the relative standard deviation of peaks between replicate samples from the same sample batch and skin region. 


\section{Results and discussion}

\subsection{Duration based skin sampling}

Alignment of the six skin samples and respective quality control samples resulted in the generation of a chromatographic peak list containing 2624 peak markers. Removal of peak markers also found in quality control blanks and laboratory background samples reduced this number to 332 entries. The total number of peaks which were successfully found and aligned in each configuration and for each time interval was quantified. The skin volatile peaks collected in each sample were grouped into three groups according to their retention by the PDMS stationary phase of the first dimension of the chromatographic set-up. Groups were arbitrarily chosen to include those peaks with primary retention times $\left(T_{R_{1}}\right)$ between $0-750 \mathrm{~s}, 750-1600 \mathrm{~s}$ and $1600-2100 \mathrm{~s}$. The number of peak table entries in each retention time window and their contribution to the total number of peak table entries after each sampling duration are colour coded in Figure 3. From these results, it can be observed that the numbers of peak table entries from all three retention times windows are similar after 4.5 hours of sampling. The major differences between the total number of peak table entries before this threshold duration of sampling are due to the number of peak table entries present in the low and medium retention time windows, green and red bars respectively. It is thus evident that sampling times of at least 4.5 hours are required in order to achieve detectible signals, of as broad a range of unknown skin volatile compounds as possible, including those with low partitioning coefficients between the atmosphere and the PDMS passive sampler.

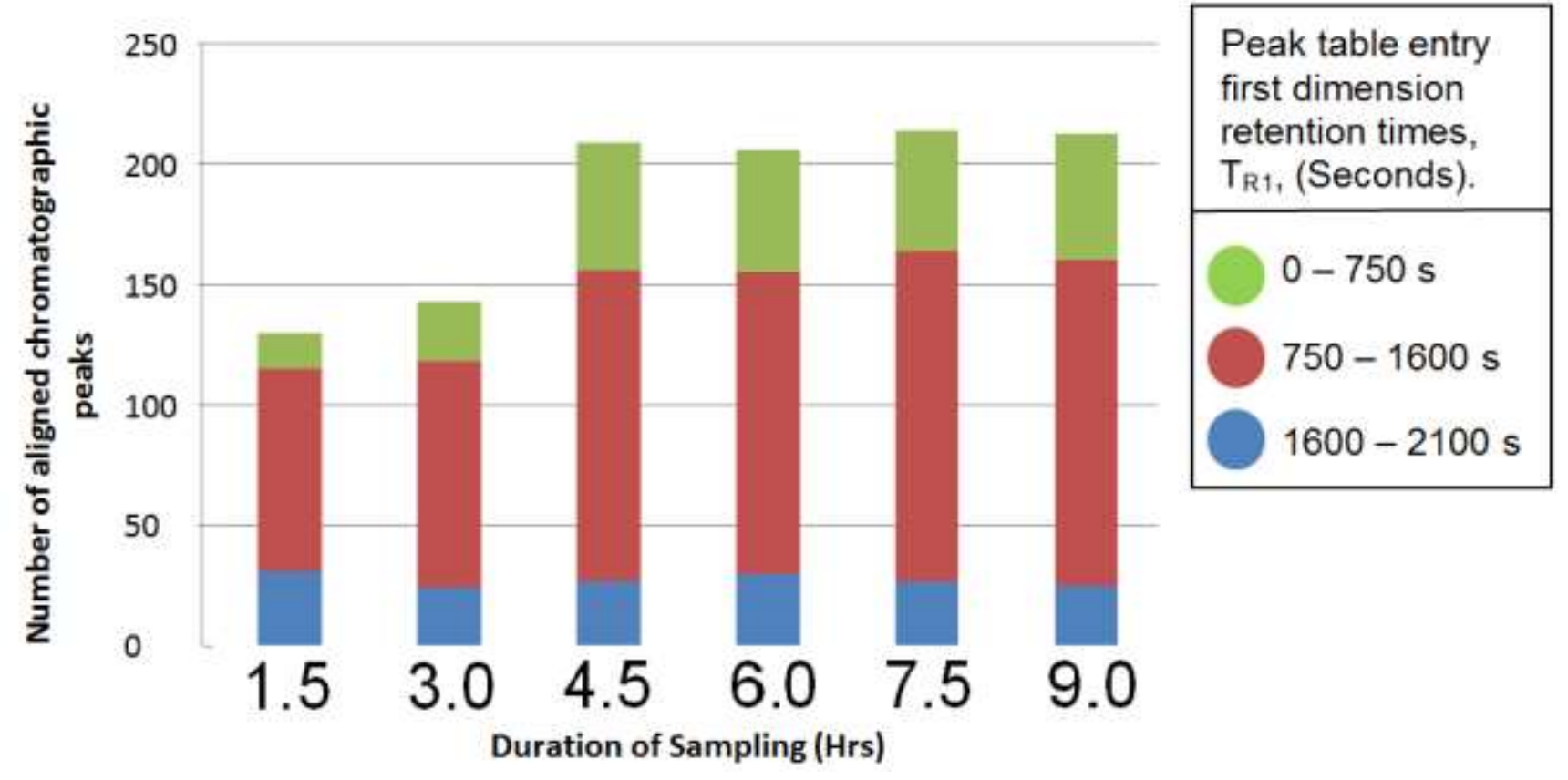

Figure 3. The number of chromatographic peaks detected exclusively in skin samples relative to the duration of sampling. Bars are colour coded according to the total numbers of entries which fall between specific retention times in the first dimension (1D). These are peak table entries with retention times between $0-750 \mathrm{~s}$ (green), $750-1600 \mathrm{~s}$ (red) and 1600 -2100 s (blue). 


\subsection{Untargeted screening}

Analysis of the volatile compounds absorbed by the PDMS loop samplers during sampling of human skin was performed by GC $\times$ GC-ToFMS analysis. This approach gives access to time-weighted average abundances of a broad range of analytes which are analysed simultaneously. During the initial development performed by our group for the use of PDMS loops as collection devices for skin volatiles, different arrangements of skin samplers were investigated. This included arrangements of the PDMS loops in both direct contact with the skin surface or held in a sampling device (not shown here) which limits the direct contact of the loops with the skin surface. The different arrangements where compared based on the complexity of the chromatograms obtained with respect to the resolution of chromatographic peaks and performance of the alignment software in each case. This work lead to the conclusion that the deconvolution process and peak alignment was affected only minimally by the added complexity of chromatograms obtained from samplers used in direct contact with the human skin. For these reasons the direct skin contact sampling approach was selected as the simplest. This approach also is the least invasive to the sampled subject as well as the topography and microbial ecosystem of the skin surface. Passive sampling using this approach yielded in the region of a thousand chromatographic peaks, from each sampled region of skin, after peaks were categorised as potential skin volatiles during initial data processing. Compounds from a broad range of chemical classes were tentatively identified based on library matches and further confirmed by corresponding first dimension linear retention indices during untargeted screening of the chromatograms (Table 1). Peaks corresponding to cosmetic products were removed from the data set. Annotated chromatograms of a human wrist sample (Figure 4) and a human ankle (Figure 5) are shown. Many of the peaks in the chromatograms did not yield satisfactory mass spectral similarity to compounds in the libraries and thus are not discussed further in this report.

Table 1. Chemical compounds as originating from the wrist and ankle skin surfaces of two sampled individuals after TD-GC $\times$ GC-ToFMS analysis of PDMS passive samplers.

\begin{tabular}{|c|c|c|c|c|c|c|c|}
\hline Number & Compound & $\begin{array}{l}\text { Unique } \\
\text { Mass (Da) }\end{array}$ & $\begin{array}{l}\text { CAS } \\
\text { number }\end{array}$ & 1D' Rt(s) & $2 D^{2} R t(s)$ & $\mathbf{R} \mathbf{I}_{\text {Calc }}{ }^{3}$ & $\mathbf{R I}_{4} \mathbf{R I}_{\text {Lit }}$ \\
\hline & Saturated straight chained carboxylic acids & & & & & & \\
\hline 1 & Acetic acid & 60 & 64-19-7 & 154 & 0.64 & 646 & 646 \\
\hline 2 & Propanoic acid & 74 & 79-09-4 & 193 & 0.71 & 704 & 715 \\
\hline 3 & Butanoic acid & 60 & $107-92-6$ & 253 & 0.77 & 792 & 795 \\
\hline 4 & Hexanoic acid & 60 & $142-62-1$ & 425 & 0.90 & 975 & 973 \\
\hline 5 & Heptanoic acid & 60 & $111-14-8$ & 512 & 0.91 & 1067 & 1063 \\
\hline 6 & Octanoic acid & 60 & $124-07-2$ & 598 & 0.93 & 1158 & 1158 \\
\hline 7 & Nonanoic acid & 60 & $112-05-0$ & 681 & 0.95 & 1255 & 1268 \\
\hline 8 & Decanoic acid & 60 & $334-48-5$ & 759 & 0.96 & 1352 & 1347 \\
\hline 9 & Dodecanoic acid & 60 & $143-07-7$ & 906 & 0.98 & 1547 & 1556 \\
\hline 10 & Tridecanoic acid & 60 & $638-53-9$ & 975 & 0.97 & 1645 & $N / A^{5}$ \\
\hline 11 & Tetradecanoic acid & 60 & $544-63-8$ & 1041 & 0.99 & 1745 & 1748 \\
\hline 12 & Pentadecanoic acid & 73 & $1002-84-2$ & 1103 & 0.98 & 1842 & 1839 \\
\hline 13 & Hexadecanoic acid & 89 & $57-10-3$ & 1164 & 1.01 & 1945 & 1942 \\
\hline 14 & Heptadecanoic acid & 60 & $506-12-7$ & 1221 & 0.97 & 2045 & 2039 \\
\hline \multirow[t]{2}{*}{15} & Octadecanoic acid & 227 & $57-11-4$ & 1275 & 0.98 & 2144 & 2142 \\
\hline & Other carboxylic acids & & & & & & \\
\hline 16 & Butanoic acid, 3-methyl- & 60 & $503-74-2$ & 298 & 0.79 & 841 & 851 \\
\hline 17 & Hexanoic acid, 2-ethyl- & 61 & $149-57-5$ & 553 & 0.89 & 1110 & $N / A^{5}$ \\
\hline 18 & 9,12-Octadecadienoic acid (Z,Z)- & 67 & $60-33-3$ & 1257 & 1.08 & 2111 & 2106 \\
\hline 19 & $\begin{array}{l}\text { Benzoic acid } \\
\text { Saturated straight chained aldehydes }\end{array}$ & 122 & $65-85-0$ & 594 & 1.21 & 1154 & 1160 \\
\hline 20 & Hexanal & 57 & $66-25-1$ & 240 & 0.86 & 773 & 780 \\
\hline 21 & Heptanal & 91 & $111-71-7$ & 331 & 0.92 & 876 & 874 \\
\hline 22 & Octanal & 105 & $124-13-0$ & 429 & 0.96 & 978 & 981 \\
\hline 23 & Nonanal & 57 & $124-19-6$ & 525 & 0.97 & 1081 & 1081 \\
\hline \multirow[t]{2}{*}{24} & Decanal & 57 & $112-31-2$ & 618 & 0.97 & 1181 & 1184 \\
\hline & Unsaturated straight chained aldehydes & & & & & & \\
\hline
\end{tabular}


2-Furancarboxaldehyde, 5-methyl-

Benzaldehyde

Benzeneacetaldehyde

Saturated straight chained ketones

2-Heptanone

2-Octanone

2-Nonanone

2-Decanone

2-Undecanone

2-Dodecanone

2-Tridecanone

2-Pentadecanone

2-Hexadecanone

Unsaturated branched chained ketones

5-Hepten-2-one, 6-methyl-

6-Methyl-3,5-heptadiene-2-one

2-Undecanone, 6,10-dimethyl-

Geranyl acetone

Other ketones

Acetophenone

Benzophenone

2,3-Pentanedione

1-Hydroxy-2-butanone

Furyl hydroxymethyl ketone

4H-Pyran-4-one, 2,3-dihydro-3,5-dihydroxy-6-

methyl-

Ethanone, 1-(2-furanyl)-

Ethanone, 1-(4-methylphenyl)-

70

55

95

110

106

91

\section{Five member ring ketones}

Cyclopentanone

2-Cyclopenten-1-one

Cyclopent-4-ene-1,3-dione

2-Cyclopenten-1-one, 2-methyl-

2-Cyclopenten-1-one, 3-methyl-

Saturated straight chained aliphatic alcohols

1-Butanol

1-Octanol

1-Nonanol

Saturated branched chained aliphatic alcohols

7-Octen-2-ol, 2,6-dimethyl-

Benzene ring containing alcohols

Phenol

Phenol, 2-methyl-

Benzyl alcohol

$p$-Cresol

Benzenemethanol, $\alpha, \alpha$-dimethyl-

Lactones

2(3H)-Furanone, 5-methyl-

Butyrolactone

2(5H)-Furanone

2(3H)-Furanone, 5-butyldihydro-

2(3H)-Furanone, 5-hexyldihydro-

2(3H)-Furanone, 5-heptyldihydro-

Terpenes

Linalool

a-Pinene

Limonene

Nitrogen containing compounds

Benzonitrile

Pyrrole

Pyridine

Indole

Indole, 3-methyl-

5,10-Diethoxy-2,3,7,8-tetrahydro-1H,6H-

dipyrrolo[1,2- $\left.\alpha: 1^{\prime}, 2^{\prime}-\delta\right]$ pyrazine

Sulphur containing compounds

$\begin{array}{ccccc}123-73-9 & 144 & 0.78 & 631 & 624 \\ 2548-87-0 & 480 & 1.05 & 1032 & 1032 \\ 18829-56-6 & 573 & 1.05 & 1132 & 1137 \\ 2497-25-8 & 663 & 1.04 & 1233 & 1229 \\ 2463-77-6 & 753 & 1.09 & 1344 & 1346 \\ & & & & \\ 98-01-1 & 265 & 1.24 & 808 & 804 \\ 620-02-0 & 384 & 1.37 & 931 & 926 \\ 100-52-7 & 381 & 1.35 & 928 & 925 \\ 122-78-1 & 456 & 1.44 & 1006 & 1011 \\ & & & & \\ 110-43-0 & 324 & 0.91 & 869 & 863 \\ 111-13-7 & 420 & 0.95 & 969 & 966 \\ 821-55-6 & 516 & 0.96 & 1071 & 1070 \\ 693-54-9 & 606 & 0.97 & 1168 & \mathrm{~N} / \mathrm{A}^{5} \\ 112-12-9 & 693 & 0.97 & 1270 & 1274 \\ 6175-49-1 & 777 & 0.96 & 1374 & 1373 \\ 593-08-8 & 852 & 0.96 & 1473 & \mathrm{~N} / \mathrm{A}^{5} \\ 2345-28-0 & 996 & 0.95 & 1677 & 1682 \\ 18787-63-8 & 1062 & 0.95 & 1777 & 1778 \\ & & & & \\ 110-93-0 & 414 & 1.03 & 963 & 963 \\ 1604-28-0 & 522 & 1.19 & 1077 & 1076 \\ 1604-34-8 & 786 & 0.93 & 1385 & \mathrm{~N} / \mathrm{A}^{5} \\ 3796-70-1 & 819 & 1.06 & 1429 & 1426 \\ & & & & \\ 98-86-2 & 480 & 1.43 & 1032 & 1033 \\ 119-61-9 & 933 & 1.72 & 1584 & 1577 \\ 600-14-6 & 166 & 0.75 & 664 & 669 \\ 5077-67-8 & 222 & 0.98 & 747 & 748 \\ 17678-19-2 & 495 & 1.51 & 1049 & 1056 \\ 28564-83-2 & 558 & 1.39 & 1116 & 1107 \\ 1192-62-7 & 336 & 1.28 & 881 & 882 \\ 122-00-9 & 591 & 1.40 & 1152 & 1157\end{array}$

120-92-3

930-30-3

930-60-9

1120-73-6

2758-18-1

71-36-3

$111-87-5$

143-08-8

162

501

591

1.09

1.32

104-76-7

108-95-2

95-48-7

100-51-6

106-44-5

617-94-7

591-12-8

497-23-4

104-50-7

706-14-9

78-70-6

80-56-8

100-47-0

120-72-9

83-34-1

678

Not

1107 
${ }^{1}$ First dimension retention time and ${ }^{2}$ second dimension retention time. ${ }^{3}$ Linear Retention Index values calculated for average first dimension retention times (1D) of replicate skin samples $(n=10) .{ }^{4}$ Values correspond to references: [23 -55$] .{ }^{5}$ Linear retention index not available.

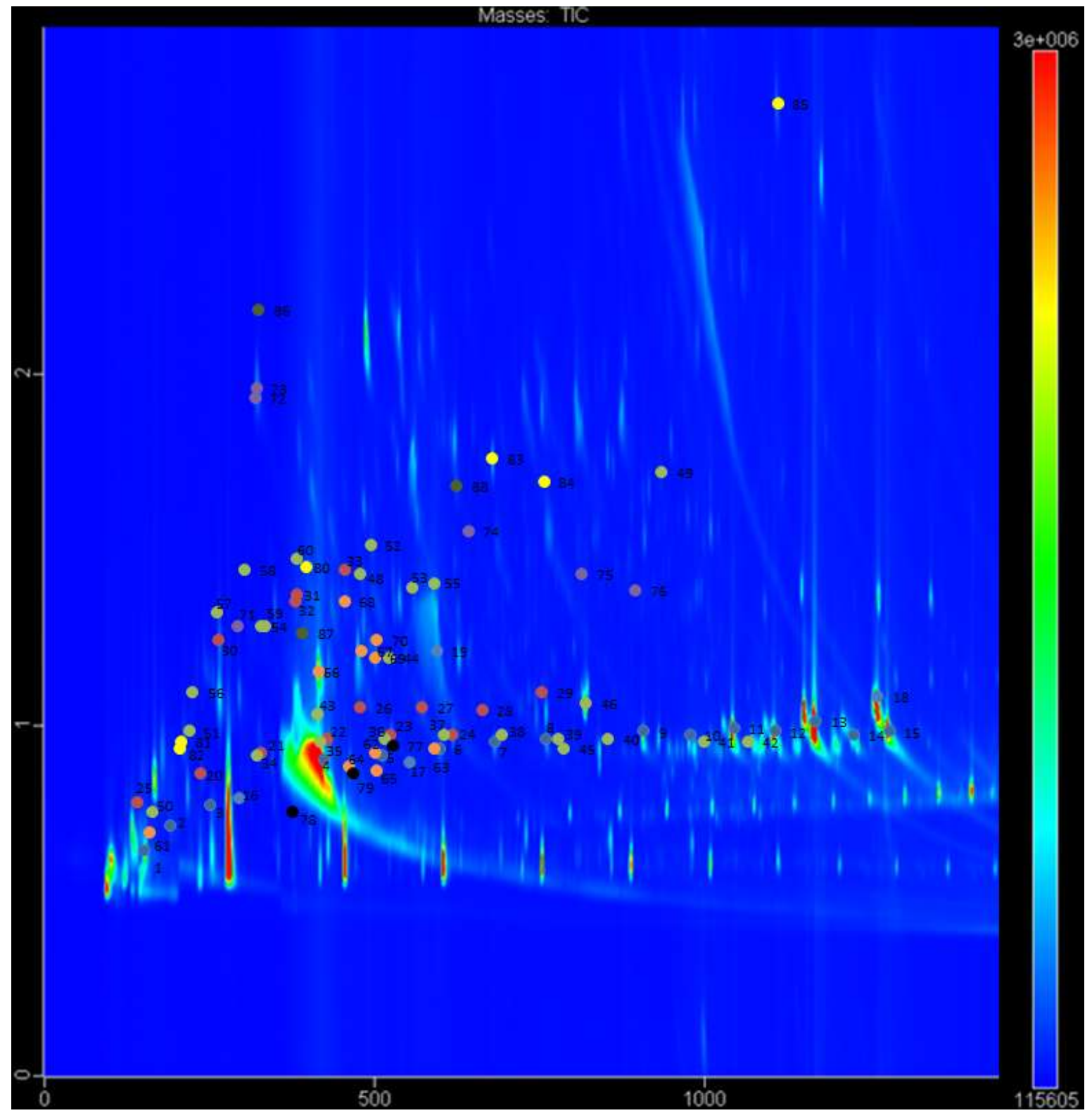

Figure 4. Total Ion Chromatogram (TIC) obtained from the GC×GC-ToF analysis of subject one's wrist. Compounds of interest are numbered according to Table 1. Compounds are grouped according to class, namely, carboxylic acids (light blue), aldehydes (red), ketones (light green), alcohols (orange), lactones (purple), terpenes (black), nitrogen containing (yellow) and sulphur containing (dark green). 


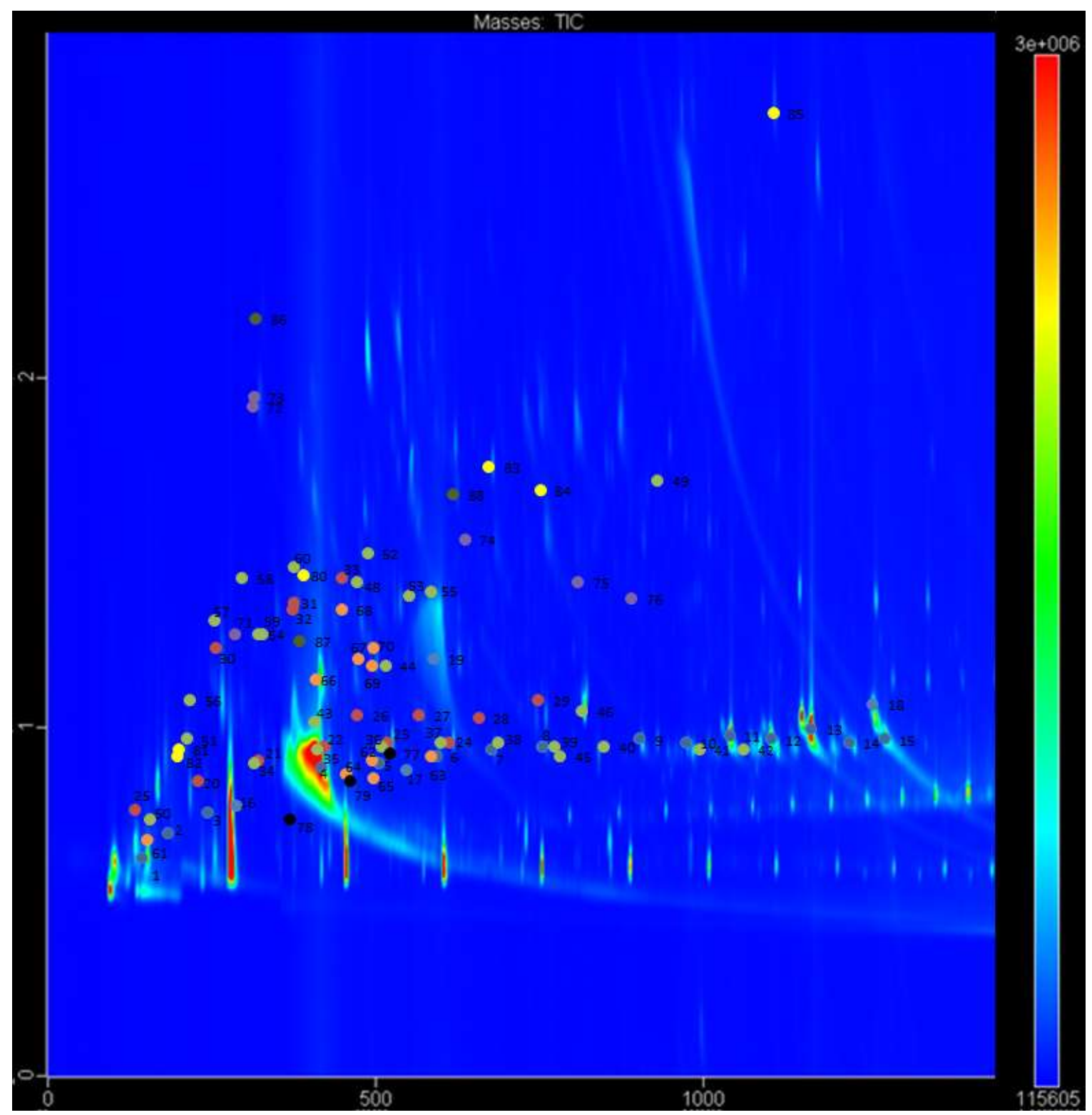

Figure 5. Total lon Chromatogram (TIC) obtained from the GC×GC-ToF analysis of subject one's ankle. Compounds of interest are numbered according to Table 1. Compounds are grouped according to class, namely, carboxylic acids (light blue), aldehydes (red), ketones (light green), alcohols (orange), lactones (purple), terpenes (black), nitrogen containing (yellow) and sulphur containing (dark green).

\subsection{Data analysis - Normalization}

In order to compare the relative abundances of selected compounds between different skin regions and individuals, a process for the normalization of peak areas is required. This is essential to reduce the effects of methodological variability and to compensate for the different sorptive volumes and surface areas of bracelet and anklet samplers. The use of PDMS loops as passive samplers for human skin volatiles does not easily allow for the inclusion of spiked standards which can be evaluated for recovery and used for normalization of signals, therefore an alternative strategy must be used. For this reason a global normalization of all chromatographic peak areas in each sample was performed. The four sets of replicate skin analyses were compared when normalized using (i) the MSTUS of each chromatogram in a sample set or (ii) the masses of 
each individual PDMS sampler loop. The \%RSDs of peak areas for replicate samples in each case are summarized as box-and-whisker plots in Figure 3.

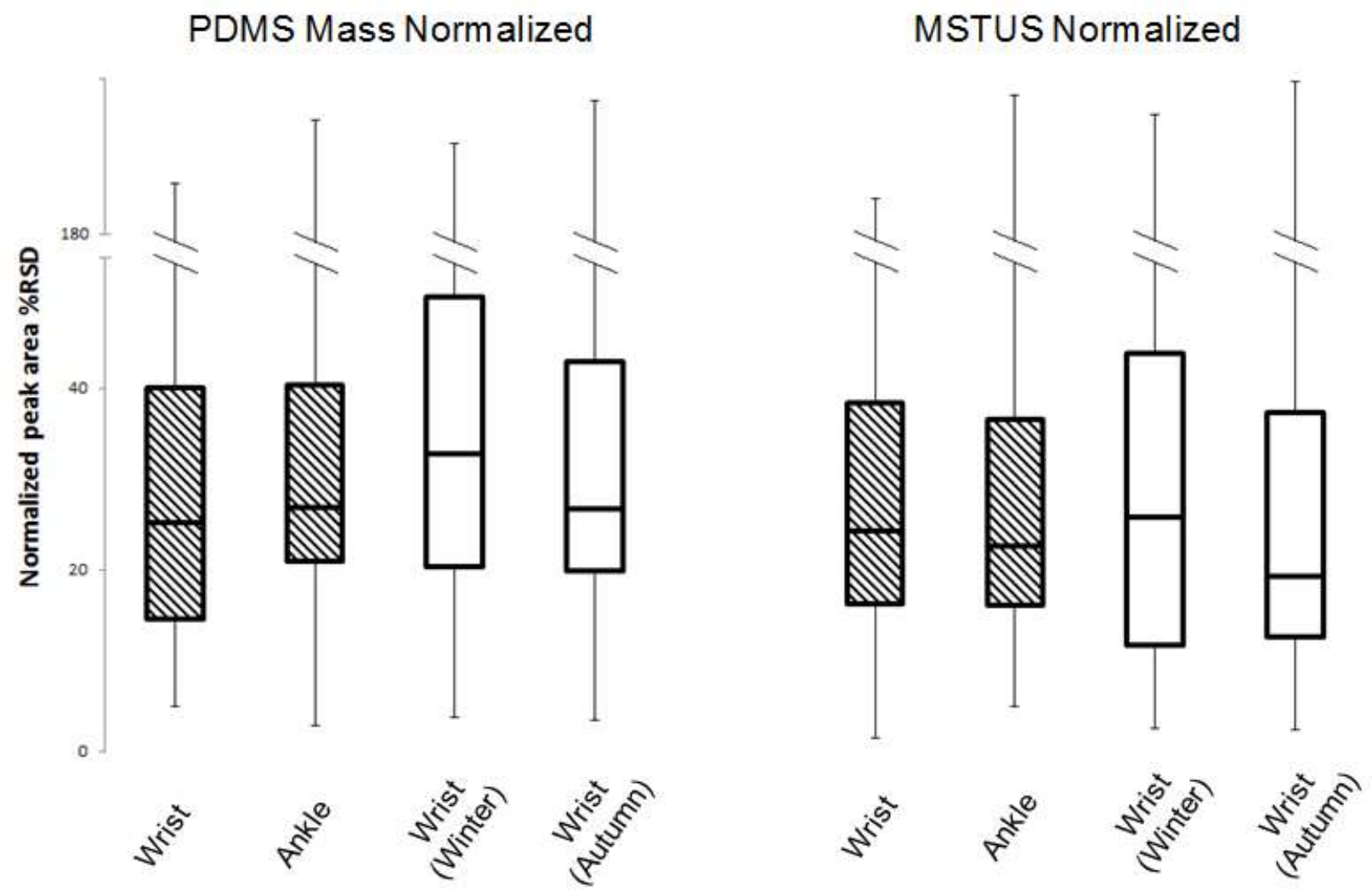

Figure 6. Box-and-whisker plots for reconstructed ion chromatogram (RIC) peak area \%RSDs of approximately 900 skin volatile chromatographic peaks found in samples collected from the ankle and wrist of Subject 1 (Textured) and the wrist of a sampled Subject 2 (White) $(n=5)$. Peak areas were normalized based on the mass of PDMS in each sampler (Left) or the Mass Spectrometry Total Useful Signal, MSTUS, (Right).

Normalization using the mass of PDMS in each sampler or the MSTUS of each sample show similar trends for the variability in the areas of peaks of replicate analyses in both sampling environments. Chromatographic peak areas in all samples compared showed lower and more consistent variability in the peak areas when normalized using the MSTUS for each sample. This result is consistent with that reported for the normalization of exhaled human breath volatiles [21].

\subsection{Peak area variability}

Precision of an analysis is important for the validity of feature detection and potential biomarker discovery in metabolomics studies comparing relative abundances of analytes between samples. In order to evaluate PDMS loop passive samplers for the collection of human skin volatiles, the reproducibility of measurements was assessed in controlled and uncontrolled environments. The validity of the data collected in a temperature controlled laboratory environment was assessed by determining the precision of the method when analysing 
replicate skin VOC samples. Relative standard deviations (RSDs) for the approximately 900 chromatographic peaks aligned in wrist and ankle samples were below $40 \%(n=5)$ for $75 \%$ of peaks when normalized using the MSTUS of each sample (Figure 3). In comparison, the variation in normalized analyte peak areas of replicate samples collected from an individual in a non-temperature controlled environment was much greater (Figure 3). The $\%$ RSD for normalized peak areas was below $45 \%(n=5)$ for $75 \%$ of analyte peaks in these sample sets when normalized using the MSTUS. The differences in repeatability of measurement between samples collected in the two different environments are likely the result of temperature differences. The passive diffusion of organic compounds into PDMS is a weak function of temperature [56]. The samplers which were worn in the temperature controlled environment exhibit better repeatability. This highlights the importance for control over external environmental parameters during the long time intervals involved for the passive collection of skin volatiles in order to ensure that results from subsequent data mining and comparisons between samples are representative of changes in the skin volatilome.

\subsection{Human skin VOC profile}

Many of the volatile compounds emanating from the surfaces of human skin originate from microbial growth on the skin's surface. The study of volatiles emitted by bacteria on the skin surface is currently limited by the complications involved with growing representative bacterial colonies using traditional culturing techniques. Not all bacterial strains found on the skin surface are amenable to laboratory based cultures [57]. In addition, the growth media used for these cultures also has an influence on the volatile profiles of the bacteria colonies [58]. One potential application of skin volatile profiling is to facilitate in the identification of bacteria specific volatiles. This has potential to aid the exploration of the complex relationships which exist between the human host, resident skin microbiome and human blood host seeking insects. Carboxylic acids and ketones were found to be the most abundant groups of compounds which were tentatively identified during the untargeted screening of skin volatiles in both sampled subjects (Table 1). Many of the carboxylic acids tentatively identified have been previously reported by researchers collecting human skin chemicals on glass beads in conjunction with GC-MS analysis [59]. The branched 3-methylbutanoic acid is present in the headspace of a wide range of skin borne Staphylococcaceae and some Corynebacteriaceae bacterial strains [3]. Among the ketones identified, the odd numbered straight chained methyl ketones 2-nonanone, 2-undecanone, 2-tridecanone and 2pentadecanone (Table 1) have also been identified as volatiles released by several skin borne bacterial strains [3]. A series of cyclic ketones (Table 1) were identified which have not been previously reported in skin VOC literature to the best of the authors' knowledge. This included cyclopentanone and a range of $\alpha, \beta$-unsaturated derivatives thereof. These compounds may be of bacterial origin [60]. Aldehydes tentatively identified in the skin samples included a range of short chain length $\left(\mathrm{C}_{6}-\mathrm{C}_{10}\right)$ saturated straight chained aldehydes. High emission rates for these compounds from human skin were reported [61]. The majority of alcohols identified in the skin samples are well known to skin VOC literature [1, 7]. In addition, benzyl alcohol and 1-butanol have been detected in the headspace of cultured S. epidermis [62]. A series of butanolides (Table 1) were identified which have been previously reported in the volatiles found in the headspace of skin borne bacterial species [63]. The terpenes limonene, $\alpha$-pinene and linolool (Table 1) have been reported in many skin volatile studies. Members of this class are however abundant in fragrances and food stuff [1]. Nitrogen containing compounds, 
benzonitrile and pyrrole have been reported in the headspace of medically important pathogenic bacteria species Pseudomonas aeruginosa [64]. Indole arises from the bacterial degradation of tryptophan [65]. The tentatively identified 5,10-diethoxy-2,3,7,8-tetrahydro-1H,6H-dipyrrolo[1,2- $\alpha: 1^{\prime}, 2$ '-ס]pyrazine has not previously been reported in human skin secretions to the best of the authors' knowledge. It has, however, been reported as a bacterial natural product [66]. Bacterial action may convert methionine to dimethyl trisulphide [67], an elevated level of this compound has been suggested as a marker for pathogenic Pseudomonas aeruginosa [68].

\subsection{Investigation of anthropophilic mosquito semiochemicals}

Another important application for the study of skin volatiles is the effect these compounds have on the bloodhost seeking behaviour of anthropophilic mosquito species. Olfaction is thought to play an important role in host detection by blood feeding mosquitoes. Skin secretions play a critical role in the selection of human blood hosts [69] and biting site preference [12] by these mosquitoes. Several analytes were selected from the skin VOC data based on their reported ability to invoke either an electrophysiological or behavioural response from the anthropophilic blood-host seeking mosquito species Anopheles gambiae sensu stricto or Aedes aegypti. Relative abundances of these compounds were compared between the ankles and wrists of two sampled individuals (Figure 4). Aliphatic carboxylic acids have been widely studied for their potential role in the host seeking behaviour of anthropophilic blood feeding mosquitoes [70 - 74]. Among the aliphatic ketones 6-methyl5-hepten-2-one has attracted interest as a potential olfactory cue for An. gambiae [75 - 78] and Ae. aegypti [5] mosquitoes, but has also been shown to exhibit a repellent effect [79]. Geranyl acetone and 6-methyl-3,5heptadiene-2-one have been detected in incubated sweat samples which elicit a response in electroantennography (EAG) measurements for An. gambiae [76]. The branched aliphatic alcohols, 2-ethyl-1hexanol and 2,6-dimethyl-7-octen-2-ol, have been shown to generate a response in EAG studies involving Ae. aegypti [5]. Compounds containing a phenol moiety have been found to generate a response in electrophysiological studies for An. gambiae [75]. Benzaldehyde and linalool have been found to elicit a response in EAG experiments involving Ae. aegypti [5]. The latter can also be a repellent for An. gambiae [76]. Indole and 3-methylindole have been shown to elicit a response in EAG studies involving An. gambiae mosquitoes $[75,76]$ and indole has been found to have a concentration dependent role in the reduction of the attractiveness of an attractant mixture of skin derived compounds in behavioural experiments [77]. Olfactory neurons in Ae. aegypti and An. gambiae are sensitive to pyridine [80]. Benzothiazole elicits an EAG response for An. gambiae [81]. 


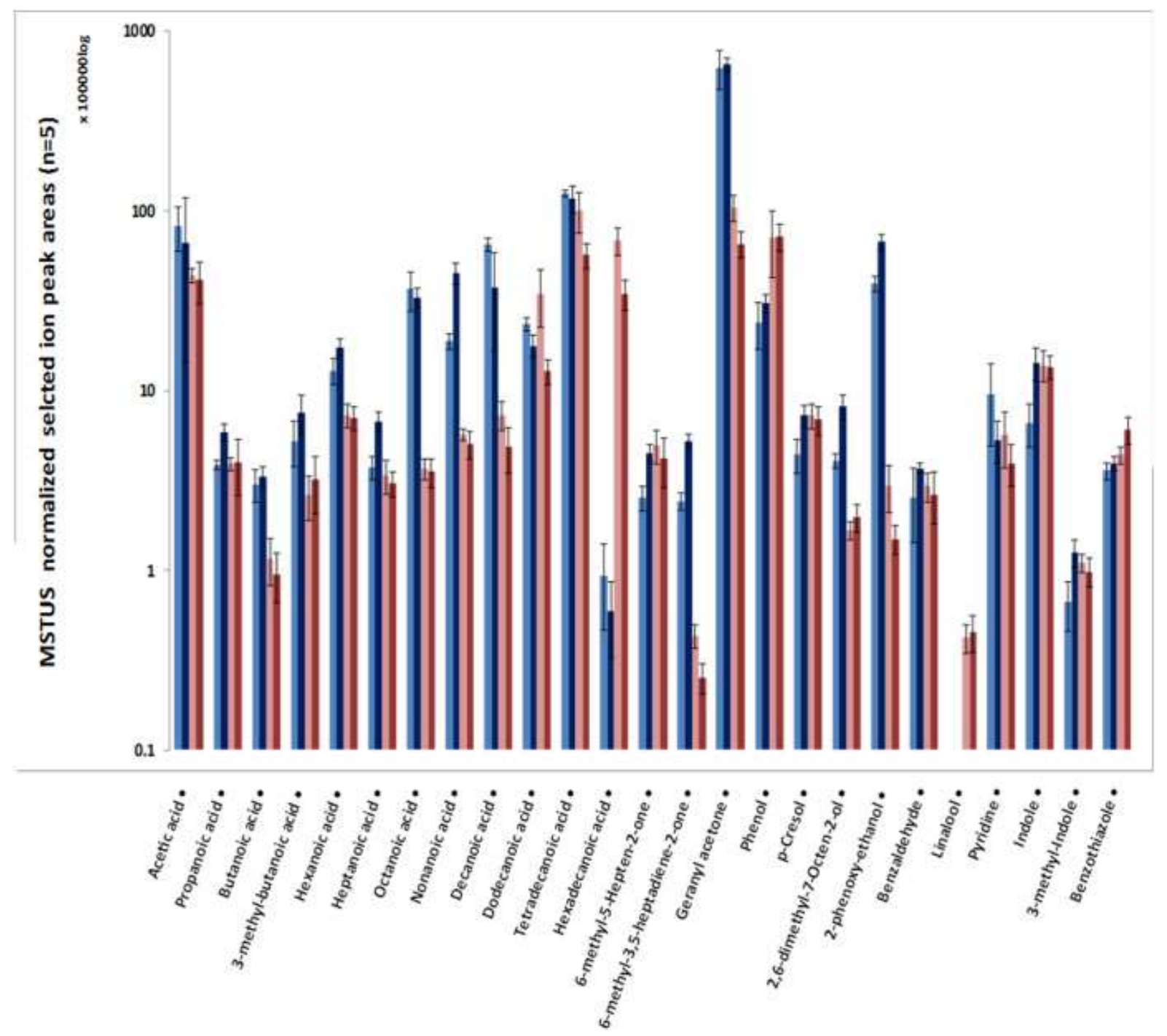

Figure 7. Log MSTUS normalized relative abundances of volatile compounds emanating from the surfaces of human wrists (light red) and ankles (red) of Subject 1 ("repellant") as well as the wrists of Subject 2 ("attractive") over three months (light (month 1) and dark blue (month 3) respectively) which have been reported to elicit a behavioural or electrophysiological response for anthropophilic mosquito species. Error bars indicate the variation in peak area of five replicate analyses.

The comparison of log normalized average analyte peak areas (Figure 4.) reveals clear differences and similarities in abundances of the selected compounds between the wrist and ankles of the sampled individuals and as well as between individuals (Figure 4). Aliphatic carboxylic acids with short chain lengths, $\mathrm{C}_{2}-\mathrm{C}_{9}$, were found to have very similar abundances in both sampled regions while longer chain lengths, $C_{10}-C_{16}$, were more abundant in the wrist sample. Tetradecanoic acid $\left(\mathrm{C}_{14}\right)$ has been found to play an important role in the formulation of synthetic blends which are attractive to the major malaria vector An. gambiae [81]. Differences such as this may play a role in the biting site preference of anthropophillic blood host seeking mosquito species. Among the ketones, geranyl acetone and 6-methyl-3,5-heptadiene-2-one were more abundant in the wrist sample than the ankle. Subject 2 ("attractive") was observed to have higher abundances of medium length long chained volatile fatty acids, $\mathrm{C}_{10}-\mathrm{C}_{12}$, as well as geranyl acetone as part of their volatile profile when compared to Subject 1 ("repellant"). Apart from the odd chain length carboxylic acids $\mathrm{C}_{7}$ and $\mathrm{C}_{9}$, relative 
abundances of the selected compounds were not observed to differ between the two seasons for Subject 2 . These odd chain length fatty acids are most likely of dietary origin which may contribute to the difference in abundance between the samples [82]. Of interest is that linalool was present in the wrist and ankle sampled regions of Subject 1 ("repellant"), but was not detected for Subject 2 ("attractive"). Furthermore, hexadecanoic acid was present at significant higher levels for Subject 1 ("repellant") compared to the lower levels detected for Subject 2 ("attractive"), while 2-phenoxy-ethanol was present at higher levels for Subject 2 ("attractive") compared to Subject 1 ("repellant").

\section{Conclusions}

Unravelling the human skin volatilome is still an enormous challenge as there seems to be no generally accepted method to reliably sample and analyse the complex mixture of volatile compounds emanating from the skin surface. The work presented here aimed to investigate PDMS loops (as bracelets and anklets) for the passive sampling of human skin volatiles over extended periods of time under different environmental conditions, as well as for their use in comparing relative abundances of analytes collected from different sample regions and individuals. Compared to obtrusive skin sampling methods the simplified method reported here is easy to use and has a minimal invasiveness to the skin surface, ensuring that the skin volatiles collected over long sampling periods are not influenced by the presence of the passive samplers, it is extremely comfortable to wear and does not impact on the dignity of the subject. The duration of sampling can be optimised to collect a large number of compounds present in the skin volatilome including many with low partitioning coefficients in PDMS. Comprehensive two-dimensional gas chromatography is a powerful technique for investigating complex biological samples. This technique is able to effectively separate thousands of chromatographic peaks, corresponding to compounds emanating from the skin surface, when used in combination with PDMS passive sampling loops. The full potential of this technique has yet to be fully exploited for the analysis of human skin emanations. However, potential was demonstrated by the tentative identification of several previously unreported skin volatiles, such as series of cyclic ketones and lactones as well as nitrogen containing compounds, all of which may be linked to the resident skin microbiome. The method shows acceptable precision to facilitate biomarker discovery. The use of PDMS loop passive samplers in combination with thermal desorption and two-dimensional gas chromatography thus shows promise as a method for augmenting current knowledge of the human skin volatilome. The results presented here highlight the application of the new sampling technique as a tool to study relationships between human skin and blood-host seeking mosquito vectors of human disease.

\section{Conflicts of interest}

The authors declare that they have no conflict of interest.

\section{Informed consent}

The study protocol was approved by the ethics committee of the University of Pretoria (Reference number EC160606-044) and informed consent was obtained prior to collection of the samples. 


\section{Acknowledgment}

The authors greatly acknowledge the support from Dr. Peter Gorst-Allman and Jack Cochran. The authors also wish to express their gratitude to the National Research Foundation of South Africa for providing partial funding during this research project.

\section{Role of the funding source}

National Research Foundation (NRF) of South Africa - partial financial support. No involvement in study design; in the collection, analysis and interpretation of data; in the writing of the report; and in the decision to submit the article for publication. Prof Anton Stoltz, Division of Infectious Diseases, Faculty of Health Sciences, University of Pretoria, Pretoria, South Africa. Financial sponsor, involved in study design and in the decision to submit the article for publication.

\section{References}

[1] B. de Lacy Costello, A. Amann, H. Al-Kateb, C. Flynn, W. Filipiak, T. Khalid, D. Osborne, N.M. Ratcliffe, A review of the volatiles from the healthy human body., J. Breath Res. 8 (2014) 014001.

[2] A.M. Curran, P.A. Prada, K.G. Furton, The differentiation of the volatile organic signatures of individuals through SPME-GC/ms of characteristic human scent compounds, J. Forensic Sci. 55 (2010) 50-57.

[3] M.C. Lemfack, S.R. Ravella, N. Lorenz, M. Kai, K. Jung, S. Schulz, B. Piechulla, Novel volatiles of skinborne bacteria inhibit the growth of Gram-positive bacteria and affect quorum-sensing controlled phenotypes of Gram-negative bacteria, Syst. Appl. Microbiol. 39 (2016) 503-515.

[4] L.J. Zwiebel, W. Takken, Olfactory regulation of mosquito-host interactions, Insect Biochem. Mol. Biol. 34 (2004) 645-652.

[5] J.G. Logan, M.A. Birkett, S.J. Clark, S. Powers, N.J. Seal, L.J. Wadhams, A.J. Mordue, J.A. Pickett, Identification of human-derived volatile chemicals that interfere with attraction of Aedes aegypti mosquitoes, J. Chem. Ecol. 34 (2008) 308-322.

[6] L. Dormont, J.M. Bessière, A. Cohuet, Human Skin Volatiles: A Review, J. Chem. Ecol. 39 (2013) 569-578.

[7] W. Filipiak, P. Mochalski, J. Troppmair, K. Unterkofler, A. Agapiou, C. Davis, R. Cumeras, C. Ager, A. Filipiak, A compendium of volatile organic compounds (VOCs) released by human cell lines, Curr. Med. Chem. 23 (2016) 2112 - 2131.

[8] Y. Xu, S.J. Dixon, R.G. Brereton, H.A. Soini, M. V. Novotny, K. Trebesius, I. Bergmaier, E. Oberzaucher, K. Grammer, D.J. Penn, Comparison of human axillary odour profiles obtained by gas chromatography/mass spectrometry and skin microbial profiles obtained by denaturing gradient gel electrophoresis using multivariate pattern recognition, Metabolomics. 3 (2007) 427-437.

[9] N.O. Verhulst, Y.T. Qiu, H. Beijleveld, C. Maliepaard, D. Knights, S. Schulz, D. Berg-Lyons, C.L. Lauber, W. Verduijn, G.W. Haasnoot, R. Mumm, H.J. Bouwmeester, F.H.J. Claas, M. Dicke, J.J.A. van Loon, W. Takken, R. Knight, R.C. Smallegange, Composition of human skin microbiota affects attractiveness to malaria mosquitoes, PLoS One. 6 (2011) e28991.

[10] S.K. Pandey, K.H. Kim, Human body-odor components and their determination, TrAC - Trends Anal. Chem. 30 (2011) 784-796. 
[11] A. Robinson, A.O. Busula, M.A. Voets, K.B. Beshir, J.C. Caulfield, S.J. Powerse, N.O. Verhulst, P. Winskill, J.Muwanguzi, M. A. Birkett, R.C. Smallegange, D.K. Masiga, W. R.Mukabana, R.W. Sauerwein, C.J.

Sutherland, T.Bousema, J. A. Pickett, W.Takken, J.G. Logan, J.G. de Boer, Plasmodium-associated changes in human odor attract mosquitoes, PNAS Latest Articles (2018) 1-10.

[12] C. M. De Moraes, C. Wanjiku, N.M. Stanczyk, H. Pulido, J.W. Sims, H.S. Betz, A.F. Read, B.Torto, M.C. Mescher, Volatile biomarkers of symptomatic and asymptomatic malaria infection in humans, PNAS Latest Articles (2018) 1-6.

[13] B. Grabowska-Polanowska, P. Miarka, M. Skowron, J. Sulowicz, K. Wojtyna, K. Moskal, I. Sliwka, Development of sampling method and chromatographic analysis of volatile organic compounds emited from human skin, Bioanalysis (2017).

[14] U.R. Bernier, D.L. Kline, C.E. Schreck, R.A. Yost, D.R. Barnard, Chemical analysis of human skin emanations: comparison of volatiles from humans that differ in attraction of Aedes aegypti (Diptera: Culicidae)., J. Am. Mosq. Control Assoc. 18 (2002) 186-95.

[15] N.O. Verhulst, B.T. Weldegergis, D. Menger, W. Takken, Attractiveness of volatiles from different body parts to the malaria mosquito Anopheles coluzzii is affected by deodorant compounds, Sci. Rep. 6 (2016) 27141.

[16] N.O. Verhulst, R. Andriessen, U. Groenhagen, G.B. Kiss, S. Schulz, W. Takken, J.J.A. van Loon, G. Schraa, R.C. Smallegange, Differential attraction of malaria mosquitoes to volatile blends produced by human skin bacteria, PLoS One. 5 (2010) e15829.

[17] H.J. Martin, M.A. Turner, S. Bandelow, L. Edwards, S. Riazanskaia, C.L.P. Thomas, Volatile organic compound markers of psychological stress in skin: a pilot study, J. Breath Res. 10 (2016) 046012.

[18] S. Riazanskaia, G. Blackburn, M. Harker, D. Taylor, C.L.P. Thomas, The analytical utility of thermally desorbed polydimethylsilicone membranes for in-vivo sampling of volatile organic compounds in and on human skin, Analyst. 133 (2008) 1020 - 1027.

[19] R. Jiang, E. Cudjoe, B. Bojko, T. Abaffy, J. Pawliszyn, A non-invasive method for in vivo skin volatile compounds sampling, Anal. Chim. Acta. 804 (2013) 111-119.

[20] H.J. Martin, J.C. Reynolds, S. Riazanskaia, C.L.P. Thomas, High throughput volatile fatty acid skin metabolite profiling by thermal desorption secondary electrospray ionisation mass spectrometry., Analyst. 139 (2014) 4279-4286.

[21] A. Peralbo-Molina, M. Calderón-Santiago, F. Priego-Capote, B. Jurado-Gámez, M.D. Luque de Castro, Development of a method for metabolomic analysis of human exhaled breath condensate by gas chromatography-mass spectrometry in high resolution mode, Anal. Chim. Acta. 887 (2015) 118-126.

[22] H. Van den dool, P.D. Kratz, A generalization of the retention index system including linear temperature programmed gas-liquid partition chromatography., J. Chromatogr. 11 (1963) 463-471.

[23] P. Ciccioli, A. Cecinato, E. Brancaleoni, M. Frattoni, A. Liberti, Use of carbon adsorption traps combined with high resolution gas chromatography - mass spectrometry for the analysis of polar and non-polar C4-C14 hydrocarbons involved in photochemical smog formation, J. Hi. Res. Chromatogr. 15 (1992) 78-84.

[24] R.G. Buttery, L.C. Ling, D.J. Stern, Studies on popcorn aroma and flavor volatiles, J. Agric. Food Chem. 45 (1997) 837-843.

[25] T. Habu, R.A. Flath, T.R. Mon, J.F. Morton, Volatile components of Rooibos tea (Aspalathus linearis), J. Agric. Food Chem. 33 (1985) 249-254. 
[26] C. Osorio, M. Alarcon, C. Moreno, A. Bonilla, J. Barrios, C. Garzon, C. Duque, Characterization of OdorActive Volatiles in Champa ( Campomanesia lineatifolia R. P.), J. Agric. Food Chem. 54 (2006) 509-516.

[27] M. Iranshahi, G. Amin, M.S. Sourmaghi, A. Shafiee, A. Hadjiakhoondi, Sulphur-containing compounds in the essential oil of the root of Ferula persica Wild. var. persica, Flavour Fragr. J. 21 (2006) 260-261.

[28] M.E. Dib, N. Djabou, L.-M. Desjobert, B. Allali, H.; Tabti, A. Muselli, J. Costa, Characterization of volatile compounds of Daucus crinitus Desf. headspace solid phase microextraction as alternative technique to hydrodistillation, Chem, Centr. J. 4 (2010) 1-15.

[29] J. Paolini, A. Muselli, A.-F. Bernardini, A. Bighelli, J. Casanova, J. Costa, Thymol derivatives from essential oil of Doronicum corsicum L., Flavour Fragr. J. 22 (2007) 479-487.

[30] C.I. Johnson, A. Urso, L. Geleta, Broad spectrum analysis of municipal and industrial effluents discharged into the Peace, Athabasca and Slave river basins: characterization of effluent samples, 1994 - Volume 1 of 2, Northern River Basins Study Project Report No. 121, 1997.

[31] R. Richmond, E. Pombo-Villar, Use of persistent trace gas chromatography artifacts for the calculation of pseudo-Sadtler retention indices, J. Chromatogr. A. 811 (1998) 241-245.

[32] A.B. DeMilo, C.-J. Lee, D.S. Moreno, A.J. Martinez, Identification of volatiles derived from Citrobacter freundii fermentation of a trypticase soy broth, J. Agric. Food Chem. 44 (1996) 607-612.

[33] G. Sun, P. Stremple, Retention Index Characterization of Flavor, Fragrance and Many Other Compounds on DB-1 and DB-XLB, 2003.

[34] J. Paolini, J.M. Desjobert, J. Costa, A.F. Bernardini, C.B. Castellini, P.L. Cioni, G. Flamini, I. Morelli, Composition of essential oils of Helichrysum italicum (Roth) G. Don fil subsp. italicum from Tuscan archipelago islands, Flavour Fragr. J. 21 (2006) 805-808.

[35] E.E. Stashenko, H.S. Villa, M.Y. Combariza, Comparative study of Colombian rue oils by high resolution gas chromatography using different detection systems, J. Microcolumn Sep. 7 (1995) 117-122.

[36] J. Paolini, J. Costa, A. Bernardini, Analysis of the essential oil from aerial parts of Eupatorium cannabinum subsp. corsicum (L.) by gas chromatography with electron impact and chemical ionization mass spectrometry, J. Chromatogr. A. 1076 (2005) 170-178.

[37] P.P. se Souza, Z.D. Cardeal, R. Augusti, P. Morrison, P.J. Marriott, Determination of volatile compounds in Brazilian distilled cachaca by using comprehensive two-dimensional gas chromatography and effects of production pathways, J. Chromatogr. A. 1216 (2009) 28812890.

[38] S. Cozzani, A. Muselli, J.-M. Desjobert, A.-F. Bernardini, F. Tomi, J. Casanova, Chemical composition of essential oil of Teucrium polium subsp. capitatum (L.) from Corsica, Flavour Fragr. J. 20 (2005) 436-441.

[39] A. Muselli, P.-G. Rossi, J.-M. Desjobert, A.-F. Bernardini, L. Berti, J. Costa, Chemical composition and antibacterial activity of Otanthus maritimus (L.) Hoffmanns. Link essential oils from Corsica, Flavour Fragr. J. 22 (2007) 217-223.

[40] D. Helmig, W. Pollock, J. Greenberg, P. Zimmerman, Gas chromatography mass spectrometry analysis of volatile organic trace gases at Mauna Loa Observatory, Hawaii, J. Geophys. Res. 101 (1996) 14697-14710.

[41] B.-S. Park, K.-G. Lee, G.R. Takeoka, Comparison of three sample preparation methods on the recovery of volatiles from taheebo (Tabebuia impetiginosa Martius ex DC), Flavour Fragr. J. 19 (2004) 287-292.

[42] C.-Y. Tai, C.-T. Ho, Influence of glutathione oxidation and pH on thermal formation of Maillard-type volatile compounds, J. Agric. Food Chem. 46 (1998) 2260-2265. 
[43] G. Lu, T.-H. Yu, C.-T. Ho, Generation of flavor compounds by the reaction of 2-deoxyglucose with selected amino acids, J. Agric. Food Chem. 45 (1997) 233-236.

[44] K.-G. Lee, S.-E. Lee, G.R. Takeoka, J.-H. Kim, B.-S. Park, Antioxidant activity and characterization of volatile constituents of beechwood creosote, J. Sci. Food Agric. 85 (2005) 1580-1586.

[45] P. Brat, B. Rega, P. Alter, M. Reynes, J.-M. Brillouet, Distribution of volatile compounds in the pulp, cloud, and serum of freshly squeezed orange juice, J. Agric. Food Chem. 51 (2003) 3442-3447.

[46] M.-L. Mattinen, J. Tuominen, K. Saarela, Analysis of TVOC and certain selected compounds from indoor air using GC/FID-RIM technique, Indoor Air. 5 (1995) 56-61.

[47] L.P. Chang, L.S. Sheng, M.Z. Yang, D.K. An, Retention index of essential oil in temperature-programmed capillary column gas chromatography, Acta Pharm. Sin. 24 (1989) 847-852.

[48] M. Coen, R. Engel, A. Nahrstedt, Chavicol $\beta$-D-glucoside, a phenylpropanoid heteroside, benzyl- $\beta$-Dglucoside and glycosidically bound volatiles from subspecies of Cedronella canariensis, Phytochemistry. 40 (1995) 149-155.

[49] P. Ciccioli, A. Cecinato, E. Brancaleoni, M. Frattoni, A. Liberti, Use of carbon adsorption traps combined with high resolution gas chromatography - mass spectrometry for the analysis of polar and non-polar C4-C14 hydrocarbons involved in photochemical smog formation, J. Hi. Res. Chromatogr. 15 (1992) 75-84.

[50] C.-J. Lee, A.B. DeMilo, D.S. Moreno, R.L. Mangan, Identification of the volatile components of E802 Mazoferm steepwater, a condensed fermented corn extractive highly attractive to the Mexican fruit fly (Diptera: Tephritidae), J. Agric. Food Chem. 45 (1997) 2327-2331.

[51] J. Chen, C.-T. Ho, Volatile compounds generated in serine-monosaccharide model systems, J. Agric. Food Chem. 46 (1998) 1518-1522.

[52] M. Bendahou, A. Muselli, M. Grignon-Dubois, M. Benyoucef, J.-M. Desjobert, A.-F. Bernardini, J. Costa, Antimicrobial activity and chemical composition of Origanum glandulosum Desf. essential oil and extract obtained by microwave extraction: Comparison with hydrodistillation, Food Chem. 106 (2008) 132-139.

[53] Y. Zhang, C.-T. Ho, Formation of meatlike aroma compounds from thermal reaction of inosine 5'monophosphate with cysteine and glutathione, J. Agric. Food Chem. 39 (1991) 1145-1148.

[54] S. Rochat, J.Y. de Saint Laumer, A. Chaintreau, Analysis of sulfur compounds from the in-oven roast beef aroma by comprehensive two-dimensional gas chromatography, J. Chromatogr. A. 1147 (2007) 85-94.

[55] J. Kwak, M. Gallagher, M.H. Ozdener, C.J. Wysocki, B.R. Goldsmith, A. Isamah, A. Faranda, S.S. Fakharzadeh, M. Herlyn, A.T.C. Johnson, G. Preti, Volatile biomarkers from human melanoma cells, J. Chromatogr. B Anal. Technol. Biomed. Life Sci. 931 (2013) 90-96.

[56] S. Seethapathy, T. G??recki, Polydimethylsiloxane-based permeation passive air sampler. Part II: Effect of temperature and humidity on the calibration constants, J. Chromatogr. A. 1217 (2010) 7907-7913.

[57] H.H. Kong, J.A. Segre, Skin Microbiome: Looking Back to Move Forward, J. Invest. Dermatol. 132 (2012) 933-939.

[58] R.M.S. Thorn, D.M. Reynolds, J. Greenman, Multivariate analysis of bacterial volatile compound profiles for discrimination between selected species and strains in vitro, J. Microbiol. Methods. 84 (2011) 258-264.

[59] U.R. Bernier, D.L. Kline, D. Barnard, C. Schreck, R.A. Yost, D.R. Barnard, C.E. Schreck, Analysis of Human Skin Emanations by Gas Identification of Volatile Compounds That Are Candidate Attractants for the Yellow Fever Mosquito ( Aedes aegypti ) Analysis of Human Skin Emanations by Gas Identification of Volatile Compounds That Are Candidate A, Anal. Chem. 72(4) (2000) 747-756. 
[60] C.A. Citron, P. Rabe, J.S. Dickschat, The scent of bacteria: Headspace analysis for the discovery of natural products, J. Nat. Prod. 75 (2012) 1765-1776.

[61] P. Mochalski, J. King, K. Unterkofler, H. Hinterhuber, A. Amann, Emission rates of selected volatile organic compounds from skin of healthy volunteers, J. Chromatogr. B Anal. Technol. Biomed. Life Sci. 959 (2014) 6270.

[62] N.O. Verhulst, H. Beijleveld, B.G. Knols, W. Takken, G. Schraa, H.J. Bouwmeester, R.C. Smallegange, Cultured skin microbiota attracts malaria mosquitoes., Malar. J. 8 (2009) 302.

[63] J.N. Labows, K. McGinley, G. Webster, J.J. Leyden, Characteristic gamma-lactone production of the genus Pityrosporum, Appl. Environ. Microbiol. 38 (1979) 412-415.

[64] H.D. Bean, J.D. Dimandja, J.E. Hill, Bacterial volatile discovery using solid phase microextraction and comprehensive two-dimensional gas chromatography - time-of-flight mass spectrometry, J. Chromatogr. B. 901 (2012) 41-46.

[65] W.R. Wikoff, A.T. Anfora, J. Liu, P.G. Schultz, S.A. Lesley, E.C. Peters, G. Siuzdak, Metabolomics analysis reveals large effects of gut microflora on mammalian blood metabolites, Proc. Natl. Acad. Sci. 106 (2009) 3698-3703.

[66] H. Li, L. Liu, S. Zhang, W. Cui, J. Lv, Identification of antifungal compounds produced by Lactobacillus casei AST18, Curr. Microbiol. 65 (2012) 156-161.

[67] S. Schulz, J.S. Dickschat, Bacterial volatiles: the smell of small organisms, Nat. Prod. Rep. 24 (2007) 814.

[68] L.D.J. Bos, P.J. Sterk, M.J. Schultz, Volatile Metabolites of Pathogens: A Systematic Review, PLoS Pathog. 9 (2013) 1-8.

[69] W. Takken, N.O. Verhulst, Host Preferences of Blood-Feeding Mosquitoes, Annu. Rev. Entomol. (2013) 433-453.

[70] B.G.J. Knols, J.J.A. van Loon, A. Cork, R.D. Robinson, W. Adam, J. Meijerink, R. De Jong, W. Takken, Behavioural and electrophysiological responses of the female malaria mosquito Anopheles gambiae (Diptera: Culicidae) to Limburger cheese volatiles, Bull. Entomol. Res. 87 (1997) 151.

[71] I.V.F. Van Den Broek, C.J. Den Otter, Olfactory sensitivities of mosquitoes with different host preferences (Anopheles gambiae s.S., An. arabiensis, An. quadriannulatus, An. m. atroparvus) to synthetic host odours, J. Insect Physiol. 45 (1999) 1001-1010.

[72] R.C. Smallegange, Y.T. Qiu, J.A. van Loon, W. Takken, Synergism between ammonia, lactic acid and carboxylic acids as kairomones in the host-seeking behaviour of the malaria mosquito Anopheles gambiae sensu stricto (Diptera: Culicidae), Chem. Senses. 30 (2005) 145-152.

[73] R.C. Smallegange, Y.T. Qiu, G. Bukovinszkiné-Kiss, J.J.A. Van Loon, W. Takken, The effect of aliphatic carboxylic acids on olfaction-based host-seeking of the malaria mosquito Anopheles gambiae sensu stricto, J. Chem. Ecol. 35 (2009) 933-943.

[74] E.A. Owino, R. Sang, C.L. Sole, C. Pirk, C. Mbogo, B. Torto, An improved odor bait for monitoring populations of Aedes aegypti-vectors of dengue and chikungunya viruses in Kenya., Parasit. Vectors. 8 (2015) 253.

[75] Y.T. Qiu, J.J.A. van Loon, W. Takken, J. Meijerink, H.M. Smid, Olfactory coding in antennal neurons of the malaria mosquito, Anopheles gambiae, Chem. Senses. 31 (2006) 845-863.

[76] T. Dekker, M. a Posthumus, T. a V. a N. Beek, Identification of olfactory stimulants for anopheles gambiae from human sweat samples, 26 (2000) 1367-1382. 
[77] Y.T. Qiu, R.C. Smallegange, J.J.A. Van Loon, W. Takken, Behavioural responses of Anopheles gambiae sensu stricto to components of human breath, sweat and urine depend on mixture composition and concentration, Med. Vet. Entomol. 25 (2011) 247-255.

[78] A. Hiscox, B. Otieno, A. Kibet, C.K. Mweresa, P. Omusula, M. Geier, A. Rose, W.R. Mukabana, W. Takken, Development and optimization of the Suna trap as a tool for mosquito monitoring and control, Malar. J. 13 (2014) 257.

[79] D.J. Menger, J.J.A. Van Loon, W. Takken, Assessing the efficacy of candidate mosquito repellents against the background of an attractive source that mimics a human host, Med. Vet. Entomol. 28 (2014) 407-413.

[80] G.M. Tauxe, D. Macwilliam, S.M. Boyle, T. Guda, A. Ray, Targeting a dual detector of skin and $\mathrm{CO} 2$ to modify mosquito host seeking, Cell. 155 (2013) 1365-1379.

[81] Y.T. Qiu, R.C. Smallegange, H. Smid, J.J. a Van Loon, A. Galimard, M. a Posthumus, T. Van Beek, W. Takken, GC-EAG analysis of human odours that attract the malaria mosquito Anopheles gambiae sensu stricto, Proc. Netherlands Entomol. Meet. 15 (2004) 59-64.

[82] B. Vlaeminck, V. Fievez, A.R.J. Cabrita, A.J.M. Fonseca, R. J. Dewhurst, Factors affecting odd- and branched-chain fatty acids in milk: A review, Animal Feed Science and Technology. 131 (2006) 389-417. 